\title{
Evaluating Knowledge and Stages of Nutritional Behavior Change in Diabetic Patients Covered by Comprehensive Health Service Centers in Ghayenat City in 2020
}

\author{
Abbas Khazaeinejad (iD ${ }^{1}$, Fatemeh Salmani (iD ${ }^{2}$ and Mitra Moodi (iD) ${ }^{2, *}$ \\ ${ }^{1}$ Student Committee Research, Department of Education \& Health Promotion, School of Health, Birjand University of Medical Sciences, Birjand, Iran \\ ${ }^{2}$ Social Determinants of Health Research Center, Department of Epidemiology and Biostatistics, School of Health, Birjand University of Medical Sciences, Birjand, Iran \\ "Corresponding author: Social Determinants of Health Research Center, Department of Education \& Health Promotion, School of Health, Birjand University of Medical \\ Sciences, Birjand, Iran. Email: mitra_m2561@yahoo.com
}

Received 2021 July 07; Revised 2021 July 25; Accepted 2021 August 03.

\begin{abstract}
Background: Diabetes is one of the most common chronic and non-communicable metabolic diseases and one of the major public health problems. Lifestyle and diet are remarkable factors in controlling diabetes.

Objectives: This study aimed to determine the level of knowledge and stages of nutritional behavior change in diabetic patients. Methods: In this descriptive-analytical study, a simple random sampling method was used to select 330 diabetic patients covered by comprehensive health service centers in Ghayenat city, South Khorasan Province, Iran. The research instrument addressed the participants' demographic information, knowledge, and stages of nutritional behavior change in diabetic patients. The ordinal logistic regression was used to examine factors affecting behavior change. In this regard, the significance level was set to be $\mathrm{P}<$ 0.05 .

Results: The participants' mean age was $57.86 \pm 11.72$ years, and $63.7 \%$ of the patients were female. The mean score of knowledge was $15.73 \pm 2.61$, and $52.8,16.9,8.9,11.3$, and 10.1 percent of the participants were in the maintenance, action, preparation, contemplation, and pre-contemplation stages. The ordinal Logistic regression model revealed that the main factors affecting behavior change were knowledge, level of income, and a family member with diabetes $(\mathrm{P}<0.05)$.

Conclusions: Given that about two-thirds of diabetic patients take no training course on diabetes, that above forty percent of these individuals have no proper knowledge about the disease, and that half of the patients are in the pre-maintenance stages of behavior change, holding a training course is of paramount importance for patients.
\end{abstract}

Keywords: Diabetes Mellitus, Knowledge, Eating Behavior, Stages of Change, Transtheoretical Model

\section{Background}

Diabetes is one of the most common chronic and noncommunicable metabolic diseases and one of the major public health problems. In recent years, diabetes has been as one of the biggest challenges to the health care system in most countries, including Iran. In 2019, diabetes accounted for $20.1 \%$ of deaths. Many estimates indicate that the number of individuals with diabetes will globally increase from 422 million to 642 million persons by 2040 (1, 2).

According to the American Diabetes Association, diabetes mellitus (DM) is not a disease; however, it encompasses a group of metabolic diseases characterized by hyperglycemia resulting from any defect in insulin secretion, insulin action, or both. Diabetes is classified into several categories: Type 1 diabetes, Type 2 diabetes, gestational diabetes mellitus, and others (3). Patients with DM deal with medications as well as lifestyle changes and diets. Without proper care and treatment, chronic hyperglycemia would lead to damage and complications, including retinopathy, nephropathy, diabetic foot ulcer, kidney failure, and cardiovascular diseases (4).

According to previous research, the best method to control this disease is to keep the diabetic patients' blood sugar within a normal range. Blood sugar control is highly dependent on following a proper diet among these patients (5).

The Centers for Disease Control and Prevention has defined self-dietary management as a key step in providing diabetic individuals with relevant knowledge and skill 
about the disease treatment and its nutritional aspects, medications, and complications. Sami et al.'s study on 350 types 2 diabetic cases in the Kingdom of Saudi Arabia indicated the patients' low dietary knowledge (6).

Given the current problems in creating and maintaining patients' nutritional behaviors, it is necessary to use behavior change theories and models in this field as they would reveal the main factors affecting the desired behavior (7).

The trans theoretical model (TTM) is a complete and coherent model predicting how and when the behavior changes. In this model, the behavior is assumed not to occur in a spontaneous and random stage; however, it is exhibited during a series of steps (8). TTM encompasses four constructs: Stages of Change, self-efficacy, decisional balance, and the stages of change (9). In the present study, only one of the constructs, 'the stages of change', is investigated and described. According to this model, individuals go through some steps (namely pre-contemplation, contemplation, preparation, action, and maintenance) to change their behavior. The pre-contemplation stage is realized when a person is either unaware of the behavior change or has already experienced a failed change. At this stage, individuals are usually demotivated or resistant to change.

In the contemplation stage, individuals examine the advantages and disadvantages of the behavior to change it and seek information about the desired behavior to be directed towards the right behavior. In the preparation stage, one is ready for change and is prepared to exhibit the behavior. Individuals have changed their behaviors in the action stage; however, this stage lasts less than six months. During the maintenance stage, one has changed his behavior for more than six months. This maintenance stage and the stage of action require active and conscious efforts to prevent relapse to previous behavioral stages (9). To the best of our knowledge, many studies have examined diabetic patients' nutrition using the Health Belief Model (1012). However, few studies have addressed diabetic patients' nutritional behavior using TTM in Iran $(13,14)$. Accordingly, recognizing individuals in each stage of change can be effective in designing fruitful interventions.

\section{Objectives}

This study aimed to determine the knowledge and the stages of changing nutritional behaviors among diabetic patients covered by the comprehensive health service centers in Ghayenat city in 2020.

\section{Methods}

This research was a cross-sectional descriptiveanalytical study on 330 diabetic patients covered by health centers in Ghayenat, South Khorasan Province, Iran, in 2020. The sample size was determined based on Morgan's table regarding limited communities. The list of patients on the SIB system was prepared, and random samples were selected from the list using random number generation with $\mathrm{R}$ 3.6.3 software.

The patients were randomly selected (base on a random table and codes registered on the sib system). After making contacts with selected individuals, stating the research objectives, and obtaining the participants' informed consent, a questionnaire was submitted to the patients. The research tool was a researcher-made questionnaire developed based on the research objectives, which addressed demographic information (17 items) and knowledge questions (10 items). Items dealing with the stages of change were as follows:

(1) I do not currently follow a proper diet for diabetics, and I have no plan to do so in the next six months (precontemplation stage).

(2) I do not follow a proper diet for diabetics at the moment, but I plan to do so in the next six months (contemplation stage).

(3) I do not currently follow a proper diet for diabetics, but I plan to do so in the next month (preparation stage).

(4) I am currently on a proper diet for diabetics, and I have been doing so for less than six months (action stage).

(5) I am currently on a proper diet for diabetics and have been doing so for six months or more (maintenance stage).

The validity of the questionnaire was confirmed by using the content validity method and summing up the opinions of nine faculty members and health experts (three health education, two epidemiologists, one community health, one nutritionist, one physiologist, and one internal specialist). In this regard, the content validity index was 0.95 , and content validity ratio was 0.92 . To determine the reliability of the questionnaire, the questionnaire was completed by twenty homogenous individuals, and Cronbach's alpha coefficient for the whole scale was 0.798.

Data analysis was performed with SPSS software version 19 (SPSS Inc., Chicago, Illinois, USA). Frequency and percentage were used to describe the quantitative variables, and the qualitative variables were also described by mean and standard deviation. The predictors of change stages were determined using ordinal logistic regression, 
odds ratio, and confidence interval. The significance level in all tests was set to be $\mathrm{P}=0.05$.

\section{Results}

The patients' mean age was $56.34 \pm 12.53$ years, and their mean HbA1C and F.B.S were $7.37 \pm 5.99$ and $156.45 \pm$ 53.103, respectively. The results showed that $63.7 \%(n=213)$ of the participants were male. Table 1 presents the other demographic variables for the participants, and Table 2 shows the mean scores of knowledge and different levels of knowledge among these individuals. The frequency distribution of the stages of nutritional behavior change is depicted in Figure 1. To examine the determinants of the stages of change among the study participants, the predictors were imported into the logistic regression model first separately and then simultaneously. According to Table 3, the simultaneous examination of the effect of variables in the ordinal logistic regression model revealed a significant variation in knowledge variable $(\mathrm{OR}=1.14, \mathrm{CI} 95 \%=1.03$ 1.26). In other words, with one unit increase in knowledge score, the likelihood of being at higher stages increases. Individuals with enough income are more likely to experience high levels of behavior change compared to those with insufficient income.

\section{Discussion}

Diabetes is a non-communicable disease associated with lifestyles as poor nutrition increases the likelihood of its incidence. Diabetes can be controlled by modifying a patient's knowledge and attitudes towards diets and function. These factors are considered as an integral part of comprehensive diabetes care $(1,15)$. This study aimed to determine the level of knowledge and the stages of changing nutritional behaviors among diabetic patients.

The present findings showed that $69.7 \%$ of the participants were at the action and maintenance stages, and that $21.4 \%$ were at the pre-contemplation and contemplation stages. These findings are approximately in line with those presented by Lin and Wang. In 2012, they studied 317 participants with type 2 diabetes and reported that $74 \%$ of the patients were at the action and maintenance stages, and $14 \%$ of the participants were at the pre-contemplation and contemplation stages. In other words, more than half of the patients thought of changing diets as a way to control their blood sugar (16). In contrast, in Jalilian et al.'s study, almost half of the patients were at the pre-contemplation and contemplation stages, and only $36.8 \%$ of those patients

\begin{tabular}{|c|c|c|}
\hline Variables & Frequency & Percentage \\
\hline \multicolumn{3}{|l|}{ Gender } \\
\hline Male & 121 & 36.3 \\
\hline Female & 212 & 63.7 \\
\hline \multicolumn{3}{|l|}{$\operatorname{Age}(y)$} \\
\hline$<30$ & 8 & 2.5 \\
\hline $30-59$ & 186 & 58.1 \\
\hline$\geq 60$ & 126 & 39.4 \\
\hline \multicolumn{3}{|l|}{ Marital status } \\
\hline Single & 42 & 12.7 \\
\hline Married & 290 & 87.3 \\
\hline \multicolumn{3}{|l|}{ Education } \\
\hline Illiterate & 104 & 31.5 \\
\hline Elementary & 142 & 43 \\
\hline Secondary and higher & 84 & 25.5 \\
\hline \multicolumn{3}{|l|}{ Spouse education } \\
\hline Illiterate & 68 & 24 \\
\hline Elementary & 129 & 45.6 \\
\hline Secondary and higher & 86 & 20.4 \\
\hline \multicolumn{3}{|l|}{ Family size } \\
\hline 1 & 35 & 10.6 \\
\hline 2 & 98 & 29.7 \\
\hline 3 & 84 & 25.5 \\
\hline 4 & 69 & 20.9 \\
\hline$\geq 5$ & 44 & 13.3 \\
\hline \multicolumn{3}{|l|}{ Income (Rials) } \\
\hline$<10$ million & 106 & 39 \\
\hline $10-30$ million & 103 & 38.1 \\
\hline$>30$ million & 61 & 22.9 \\
\hline \multicolumn{3}{|l|}{ Diagnosis time $(y)$} \\
\hline$<3$ & 97 & 29.8 \\
\hline $3-6$ & 98 & 30.1 \\
\hline $6-9$ & 49 & 15 \\
\hline$>9$ & 82 & 25.2 \\
\hline \multicolumn{3}{|l|}{ Income } \\
\hline Sufficient & 71 & 22.1 \\
\hline Somewhat sufficient & 135 & 42.3 \\
\hline Insufficient & 113 & 35.4 \\
\hline \multicolumn{3}{|l|}{ Type of treatment } \\
\hline Oral & 287 & 88.3 \\
\hline Insulin & 17 & 5.2 \\
\hline Both & 21 & 6.5 \\
\hline \multicolumn{3}{|l|}{ Blood sugar control time } \\
\hline Once a month & 248 & 79.7 \\
\hline Once a week & 46 & 14.8 \\
\hline Once a day & 6 & 1.9 \\
\hline More than once a day & 11 & 3.5 \\
\hline \multicolumn{3}{|c|}{ Viewpoint about blood sugar control } \\
\hline Low & 52 & 15.8 \\
\hline Medium & 137 & 41.5 \\
\hline Good & 111 & 33.6 \\
\hline Excellent & 30 & 9.1 \\
\hline \multicolumn{3}{|l|}{ Educational course } \\
\hline Yes & 118 & 37.7 \\
\hline No & 195 & 62.3 \\
\hline
\end{tabular}




\begin{tabular}{|c|c|c|c|}
\hline Knowledge & Ordinal Knowledge Levels & Frequency & Percentage \\
\hline \multirow{3}{*}{$15.73 \pm 2.61$} & Weak $(<10)$ & 25 & 7.5 \\
\hline & Medium (10 - 15) & 92 & 27.6 \\
\hline & $\operatorname{Good}(\geq 15)$ & 216 & 64.9 \\
\hline
\end{tabular}

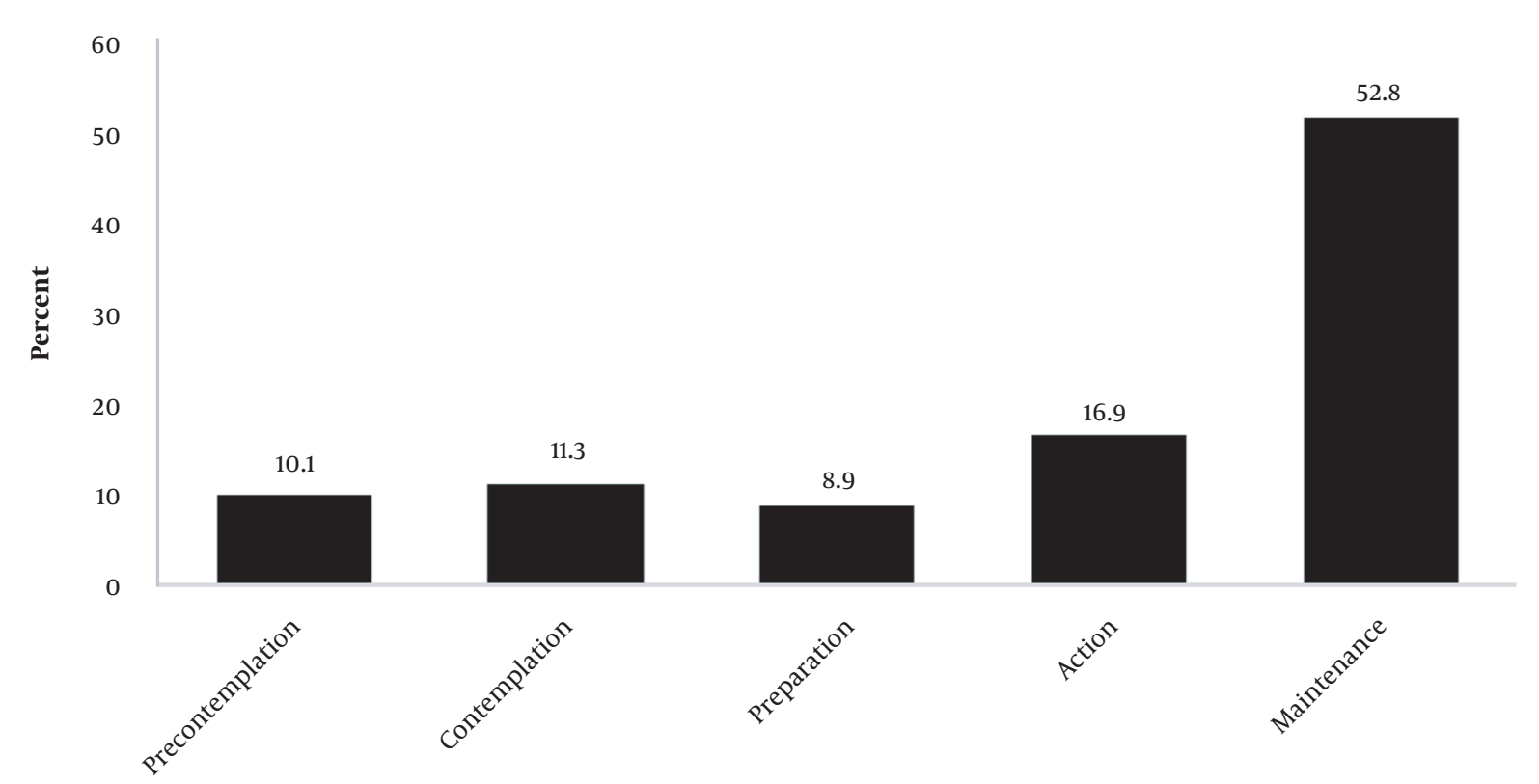

Stages of Change

Figure 1. Frequency distribution of nutritional behavior change stages in diabetic patients in the study.

were in the action stage (13). Inconsistent with the present findings, Holmen et al. showed that $79 \%$ of the participants were at the pre-action stage (17). Given the assumptions of this model, the individuals at the action and maintenance stages recognized the benefits of nutritional behavior to be more than its barriers. Furthermore, previous studies demonstrated that individuals at the action and maintenance stages benefited more social support, self-efficacy, and self-management (16-18). Accordingly, supporting and encouraging individuals at the action stage can help them move towards the maintenance stage, and individuals in the maintenance stage can be used as a model and motivators in educational classes to move individuals in the pre-contemplation and contemplation stages towards the action and maintenance stages. In our study, individuals who less controlled their blood sugar (once a month vs. more than once a day) were less likely to be in the upper stages of change. Routine control is the most important factor in changing self-management behaviors, and individuals with diabetes should regularly measure their blood sugar.

As revealed by the regression test, individuals with higher knowledge were at higher stages of behavior change (action and maintenance), indicating the positive relationship between knowledge and the stages of nutritional behavior change in diabetic patients. This finding was line with that of Chapman-Novakofski and Karduck, suggesting that patients with higher knowledge were more likely to be at the action stage (19). Inconsistent with this finding, West et al. found a significant difference between the pre-contemplation and contemplation stages in terms of knowledge and attitude (20). Previous studies have revealed that diet knowledge is a critical factor affecting diet behaviors and food choices. Studies in both developed and developing countries have indicated that knowledge of diabetes is generally low in patients with $\mathrm{DM}(21,22)$. Accordingly, designing educational interventions based on nutritional knowledge for diabet- 


\begin{tabular}{|c|c|c|c|c|c|c|c|c|c|c|c|c|}
\hline \multirow{2}{*}{ Variables } & \multicolumn{4}{|c|}{ Single Ordinal Logistic Regression } & \multicolumn{2}{|c|}{ CI 95\% } & \multicolumn{4}{|c|}{ Multiple Ordinal Logistic Regression } & \multicolumn{2}{|c|}{ CI 95\% } \\
\hline & Beta & SE & P-Value & OR & 0.025 & 0.975 & Beta & SE & P-Value & OR & 0.025 & 0.975 \\
\hline Age & 0.01 & 0.01 & 0.47 & 1.01 & 0.99 & 1.02 & 0.02 & 0.01 & 0.17 & 1.02 & 0.99 & 1.04 \\
\hline Knowledge & 0.11 & 0.04 & 0.01 & 1.11 & 1.03 & 1.20 & 0.13 & 0.05 & 0.02 & 1.14 & 1.03 & 1.26 \\
\hline \multicolumn{13}{|l|}{ Gender } \\
\hline Male & $\begin{array}{c}- \\
0.03\end{array}$ & 0.22 & 0.88 & 0.97 & 0.63 & 1.49 & 0.47 & 0.30 & 0.11 & 1.61 & 0.90 & 2.87 \\
\hline \multicolumn{13}{|l|}{ Income } \\
\hline Sufficient & 0.29 & 0.30 & 0.34 & 1.34 & 0.74 & 2.41 & 0.91 & 0.39 & 0.02 & 2.48 & 1.15 & 5.35 \\
\hline Somewhat sufficient & 0.37 & 0.31 & 0.23 & 1.44 & 0.79 & 2.62 & 0.45 & 0.37 & 0.22 & 1.57 & 0.76 & 3.23 \\
\hline \multicolumn{13}{|l|}{ Diagnosis time (y) } \\
\hline$<3$ & $\begin{array}{c}- \\
0.26\end{array}$ & 0.30 & 0.37 & 0.77 & 0.43 & 1.37 & 0.20 & 0.40 & 0.61 & 1.22 & 0.56 & 2.67 \\
\hline $3-6$ & -0.73 & 0.29 & 0.01 & 0.48 & 0.27 & 0.85 & 0.26 & 0.38 & 0.49 & 0.77 & 0.37 & 1.61 \\
\hline$>6$ & $\begin{array}{c}- \\
0.59\end{array}$ & 0.35 & 0.09 & 0.56 & 0.28 & 1.10 & -0.33 & 0.45 & 0.46 & 0.72 & 0.30 & 1.74 \\
\hline \multicolumn{13}{|l|}{ Family size } \\
\hline 1 & $\begin{array}{c}- \\
0.26\end{array}$ & 0.43 & 0.54 & 0.77 & 0.33 & 1.77 & -1.11 & 0.57 & 0.05 & 0.33 & 0.11 & 1.00 \\
\hline 2 & -0.31 & 0.35 & 0.38 & 0.74 & 0.37 & 1.45 & -0.23 & 0.46 & 0.61 & 0.79 & 0.32 & 1.95 \\
\hline 3 & $\begin{array}{c}- \\
0.07\end{array}$ & 0.36 & 0.84 & 0.93 & 0.46 & 1.88 & $\begin{array}{c}- \\
0.24\end{array}$ & 0.46 & 0.61 & 0.79 & 0.32 & 1.95 \\
\hline$\geq 4$ & 0.13 & 0.37 & 0.73 & 1.14 & 0.55 & 2.36 & 0.32 & 0.49 & 0.52 & 1.37 & 0.53 & 3.58 \\
\hline \multicolumn{13}{|l|}{ Treatment } \\
\hline Oral & 0.42 & 0.45 & .355 & 3.06 & 3.93 & 4.80 & -1.34 & 0.71 & 0.06 & 0.26 & 0.07 & 1.06 \\
\hline Insulin & -1.00 & 0.61 & .107 & 5.44 & 7.05 & 8.66 & -1.37 & 0.93 & 0.14 & 0.25 & 0.04 & 1.56 \\
\hline \multicolumn{13}{|l|}{ Blood sugar control time } \\
\hline Once a month & -1.63 & 0.82 & 0.05 & 0.20 & 0.04 & 0.97 & -1.87 & 0.94 & 0.05 & 0.15 & 0.02 & 0.97 \\
\hline Once a week & -1.37 & 0.85 & 0.11 & 0.25 & 0.05 & 1.35 & -1.74 & 0.99 & 0.08 & 0.18 & 0.03 & 1.22 \\
\hline Once a day & -0.81 & 1.18 & 0.50 & 0.45 & 0.04 & 4.54 & 0.02 & 1.44 & 0.99 & 1.02 & 0.06 & 17.12 \\
\hline \multicolumn{13}{|c|}{ Viewpoint about blood sugar control } \\
\hline Low & -2.39 & 0.52 & 0.00 & 0.09 & 0.03 & 0.25 & -2.66 & 0.71 & 0.00 & 0.07 & 0.02 & 0.28 \\
\hline Medium & -1.58 & 0.48 & 0.00 & 0.21 & 0.08 & 0.53 & -1.95 & 0.63 & 0.00 & 0.14 & 0.04 & 0.49 \\
\hline Good \& Excellent & $\begin{array}{c}- \\
0.66\end{array}$ & 0.50 & 0.18 & 0.52 & 0.19 & 1.37 & - & 0.64 & 0.29 & 0.51 & 0.14 & 1.77 \\
\hline Educational Course & -0.15 & 0.22 & & 0.86 & 0.56 & 1.32 & $\begin{array}{c}- \\
0.02\end{array}$ & 0.29 & 0.95 & 0.98 & 0.55 & 1.74 \\
\hline
\end{tabular}

ics can help complete the stages of changing the nutritional behavior. Regression analysis also suggested that individuals with higher incomes were at the higher stages of change. This finding was consistent with Mousavizadeh et al. (23) and Taha et al.'s findings (24), suggesting that financial pressure was as a barrier to the acceptance of treatment in diabetics. In contrats, Ngo-Metzger et al. reported differences in different races (25). Since cost itself is an obstacle to choosing a healthy diet, including fruits and vegetables, income is considered as a positive determinant of a healthy diet (26).

The results also indicated that patients with smaller families (one person than families with more than five members) are less likely to be at the upper stages of 
change. Individuals with diabetes need the others' support. Family members play a key role in adhering to patients' treatment and are considered as the sources of support (27). The role of family members in some studies has been demonstrated as a self-management inhibitor; hence, recognizing family members, especially girls, who can encourage and support self-management, is critical (28). As mentioned above, self-management is a remarkable factor at the action stage; hence, family members, family size, and family members' roles are effective factors in this regard.

Furthermore, the findings showed that individuals holding no positive attitudes towards glycemic control were less likely to be at the upper stages of behavior change. This finding was in line with that reported in López-Azpiazu et al.'s study on 1,009 Hispanics. They mentioned that $61.1 \%$ of patients at the pre-contemplation and relapse stages believed that they did not need to change their diets since their previous diet was healthy enough (29). Studies have documented that patients' dietary attitudes significantly affect accepting treatment and reducing the incidence of complications (30). In other words, individuals not recognizing the significant of diet change in controlling diabetes do not believe in diet change and selfcare.

\subsection{Conclusions}

According to the findings, a significant percentage of diabetic patients were at the action and maintenance stage, and promoting individuals' diet knowledge and reducing barriers such as level of income would increase the likelihood of being at the higher stages of behavior change.

\section{Acknowledgments}

This article was extracted from a master's thesis (No. 456199) and approved by the Ethics Committee (Code: ir.bums.rec.1399.121). The authors would like to thank the Deputy for Research at the Birjand University of Medical Sciences, Birjand, Iran, for their financial support and all the diabetic patients who participated in this study.

\section{Footnotes}

Authors' Contribution: Study concept and design: M. M., and A. Kh.; Data analysis and interpretation: F. S.; Drafting the manuscript: M. M., F. S, \& A. Kh.; Critical revision of the manuscript for important intellectual content: M. M. and F. S; Statistical analysis: F. S.

Conflict of Interests: The authors declare no conflict of interests in the present study.

Ethical Approval: ir.bums.rec.1399.121

Funding/Support: No Funding.

Informed Consent: All participants in this study signed the informed consent forms.

\section{References}

1. Mirzaei M, Rahmaninan M, Mirzaei M, Nadjarzadeh A, Dehghani Tafti AA. Epidemiology of diabetes mellitus, pre-diabetes, undiagnosed and uncontrolled diabetes in Central Iran: results from Yazd health study. BMC Public Health. 2020;20(1):166. doi: 10.1186/s12889-020-8267y. [PubMed: 32013917]. [PubMed Central: PMC6998152].

2. Azadnajafabad S, Mohammadi E, Aminorroaya A, Fattahi N, Rezaei S, Haghshenas R, et al. Non-communicable diseases' risk factors in Iran; a review of the present status and action plans. J Diabetes Metab Disord. 2021:1-9. doi: 10.1007/s40200-020-00709-8. [PubMed: 33500879] [PubMed Central: PMC7821170].

3. Diabetes Canada Clinical Practice Guidelines Expert C, Punthakee Z, Goldenberg R, Katz P. Definition, classification and diagnosis of diabetes, prediabetes and metabolic syndrome. Can J Diabetes. 2018;42 Suppl 1:S10-5. doi: 10.1016/j.jcjd.2017.10.003. [PubMed: 29650080].

4. Balaji R, Duraisamy R, Kumar MP. Complications of diabetes mellitus: A review. Drug Invention Today. 2019;12(1)

5. Magkos F, Hjorth MF, Astrup A. Diet and exercise in the prevention and treatment of type 2 diabetes mellitus. Nat Rev Endocrinol. 2020;16(10):545-55. doi: 10.1038/s41574-020-0381-5. [PubMed: 32690918].

6. Sami W, Alabdulwahhab KM, Ab Hamid MR, Alasbali TA, Alwadani FA Ahmad MS. Dietary knowledge among adults with type 2 diabeteskingdom of Saudi Arabia. Int J Environ Res Public Health. 2020;17(3) doi: 10.3390/ijerph17030858. [PubMed: 32019083]. [PubMed Central: PMC7037964].

7. Moodi M, Rezaeian M, Mostafavi F, Sharifirad GR. [The study of mammography screening behavior based on stage of change model in Isfahanian women of age 40 and older: A population-based study].JAdv Med Biomed Res. 2013;21(84):24-35. Persian.

8. Raihan N, Cogburn M. Stages of Change Theory. Treasure Island (FL): StatPearls Publishing; 2021.

9. Ghahramani M, Alami A, Moodi M. [Screening for cervical cancer: An educational intervention based on transtheoretical models and health belief in women of Gonabad, Iran]. Iran J Obstet Gynecol Infertil. 2018;21(5):22-32. Persian.

10. Baghernezhad Hesari BF, Sadeghi R, Momenabadi V. [The knowledge, self-efficacy, and self-care behaviors of type 2 diabetic patients referred to the diabetes clinic of Birjand, Iran]. Health Dev J. 2019;8(2):187-96. Persian.

11. Shabibi P, Zavareh MSA, Sayehmiri K, Qorbani M, Safari O, Rastegarimehr B, et al. Effect of educational intervention based on the Health Belief Model on promoting self-care behaviors of type-2 diabetes patients. Electron Physician. 2017;9(12):5960-8. doi: 10.19082/5960. [PubMed: 29560148]. [PubMed Central: PMC5843422].

12. Kolahdooz M, Hozori M, Keshavarz Mohammadi N. Comparison of knowledge and dietary behaviors in diabetics and healthy subjects in Neyshabur City (Iran). Qom Univ Med Sci J. 2018;12(10):66-75. doi: 10.29252/qums.12.10.66. 
13. Jalilian H, Pezeshki MZ, Janati A, Najafipour F, Imani A, Zozani MA, et al. Readiness for diet change and its association with diet knowledge and skills, diet decision making and diet barriers in type 2 diabetic patients. Diabetes Metab Syndr. 2019;13(5):2933-8. doi: 10.1016/j.dsx.2019.07.065. [PubMed: 31425959].

14. Abbasgholizadeh N, Mazloomi-Mahmodabadi SS, Baghianimoghadam MH, Afkhami Ardekani M, Mozaffari-Khosravi H, Nemati A, et al. [Improving nutritional behaviors of pre-diabetic patients in Yazd City: A theory-based intervention]. J health. 2013;4(3):207-16. Persian.

15. Islam SM, Niessen LW, Seissler J, Ferrari U, Biswas T, Islam A, et al. Diabetes knowledge and glycemic control among patients with type 2 diabetes in Bangladesh. Springerplus. 2015;4:284. doi: 10.1186/s40064015-1103-7. [PubMed: 26101736]. [PubMed Central: PMC4474969].

16. Lin S, Wang M. Applying the transtheoretical model to investigate behavioural change in type 2 diabetic patients. Health Educ J. 2012;72(2):189-202. doi: 10.1177/0017896912437495.

17. Holmen $\mathrm{H}$, Wahl A, Torbjornsen A, Jenum AK, Smastuen MC, Ribu L. Stages of change for physical activity and dietary habits in persons with type 2 diabetes included in a mobile health intervention: the Norwegian study in RENEWING HEALTH. BMJ Open Diabetes Res Care. 2016;4(1). e000193. doi: 10.1136/bmjdrc-2016-000193. [PubMed: 27239317]. [PubMed Central: PMC4873947].

18. Nelson KM, McFarland L, Reiber G. Factors influencing disease selfmanagement among veterans with diabetes and poor glycemic control.J Gen Intern Med. 2007;22(4):442-7. doi: 10.1007/s11606-006-00538. [PubMed: 17372790]. [PubMed Central: PMC1829424].

19. Chapman-Novakofski K, Karduck J. Improvement in knowledge, social cognitive theory variables, and movement through stages of change after a community-based diabetes education program. $J$ Am Diet Assoc. 2005;105(10):1613-6. doi: 10.1016/j.jada.2005.07.010. [PubMed: 16183364].

20. West GF, Cafferty LA, Ledford CJ. Assessing psychosocial differences in stages of change: an analysis of military healthcare system patients with type 2 diabetes. Mil Med. 2013;178(8):875-9. doi: 10.7205/MILMEDD-13-00095. [PubMed: 23929048].

21. Abdulsalam AJ, Al-Daihani AE, Francis K. Diabetes-related knowledge and preventative practices among government employees with diabetes in Kuwait. Sultan Qaboos Univ Med J. 2017;17(4):e444-51. doi: 10.18295/squmj.2017.17.04.011. [PubMed: 29372087]. [PubMed Central: PMC5766301].

22. Shrestha TM, Aacharya RP, Shrestha R, Kc M. Foot care knowledge and practice among diabetic patients attending general outpatient clinic in Tribhuvan University Teaching Hospital. Open J Endocr Metab Dis. 2017;7(8):163-71. doi: 10.4236/ojemd.2017.78015.

23. Mousavizadeh SN, Ashktorab T, Ahmadi F, Zandi M. [Evaluation of barriers to adherence to therapy in patients with diabetes]. J Diabetes Nurs. 2016;4(3):94-108. Persian.

24. Taha NM, Abd El-Azeaz MAGDA, Abd El-Razik BG. Factors affecting compliance of diabetic patients toward therapeutic management. Med J Cairo Univ. 2011;79(2).

25. Ngo-Metzger Q, Sorkin DH, Billimek J, Greenfield S, Kaplan SH. The effects of financial pressures on adherence and glucose control among racial/ethnically diverse patients with diabetes. J Gen Intern Med. 2012;27(4):432-7. doi: 10.1007/s11606-011-1910-7. [PubMed: 22005941]. [PubMed Central: PMC3304038].

26. Casagrande SS, Wang Y, Anderson C, Gary TL. Have Americans increased their fruit and vegetable intake? The trends between 1988 and 2002. Am J Prev Med. 2007;32(4):257-63. doi: 10.1016/j.amepre.2006.12.002. [PubMed: 17383556].

27. Barrera MJ, Toobert DJ, Angell KL, Glasgow RE, Mackinnon DP. Social support and social-ecological resources as mediators of lifestyle intervention effects for type 2 diabetes.J Health Psychol. 2006;11(3):48395. doi: 10.1177/1359105306063321. [PubMed: 16774900].

28. Zare M, Tarighat-Esfanjani A, Rafraf M, Shaghaghi A, AsghariJafarabadi M, Shamshiri M. The barriers and facilitators of selfmanagement among adults with type 2 diabetes mellitus: A trans theoretical model (TTM)-based mixed method study in Iran. Diabetes Metab Syndr Obes. 2020;13:2687-99. doi: 10.2147/DMSO.S230083. [PubMed: 32821141]. [PubMed Central: PMC7419615].

29. Lopez-Azpiazu I, Martinez-Gonzalez MA, Leon-Mateos A, Kearney J, Gibney M, Martinez JA. Stages of dietary change and nutrition attitudes in the Spanish population. Public Health. 2000;114(3):183-9. [PubMed: 10878745].

30. El-Khawaga G, Abdel-Wahab F. Knowledge, attitudes, practice and compliance of diabetic patients in Dakahlia, Egypt. Euro J Res Med Sci. 2015;3(1). 